Research Article

\title{
Expression and Correlation of Cell-Free cIAP-1 and cIAP-2 mRNA in Breast Cancer Patients: A Study from India
}

\author{
Amit Kumar Verma, ${ }^{1}$ Irfan Ahmad, ${ }^{2,3}$ Prasant Yadav, ${ }^{4}$ Arshad Husain Rahmani, \\ Bazila Khan, ${ }^{6}$ Mohammed A. Alsahli, ${ }^{5}$ Prakash C. Joshi, ${ }^{1}$ Hafiz Ahmad, ${ }^{7}$ \\ and Mirza Masroor Ali Beg $\oplus^{8,9}$ \\ ${ }^{1}$ Department of Zoology and Environmental Sciences, GKV, Haridwar, India \\ ${ }^{2}$ Department of Clinical Laboratory Science, College of Applied Medical Sciences, King Khalid University, Abha, Saudi Arabia \\ ${ }^{3}$ Research Center for Advanced Materials Science, King Khalid University, Abha, Saudi Arabia \\ ${ }^{4}$ Department of Biochemistry, All India Institute of Medical Sciences, Bhopal, Madhya Pradesh, India \\ ${ }^{5}$ Department of Medical Laboratories, College of Applied Medical Sciences, Qassim University, Buraydah, Saudi Arabia \\ ${ }^{6}$ School of Biotechnology, Gautam Buddha University, Noida, Uttar Pradesh, India \\ ${ }^{7}$ Department of Medical Microbiology and Immunology, RAK Medical \& Health Sciences University, Ras Al Khaimah, UAE \\ ${ }^{8}$ Department of Biochemistry, Maulana Azad Medical College, New Delhi, India \\ ${ }^{9}$ Department of Toxicology, Jamia Hamdard, New Delhi, India
}

Correspondence should be addressed to Mirza Masroor Ali Beg; mirzamasroor1986@gmail.com

Received 26 May 2020; Revised 11 August 2020; Accepted 12 August 2020; Published 25 August 2020

Academic Editor: Nihal Ahmad

Copyright (C) 2020 Amit Kumar Verma et al. This is an open access article distributed under the Creative Commons Attribution License, which permits unrestricted use, distribution, and reproduction in any medium, provided the original work is properly cited.

\footnotetext{
Background. Inhibitors of apoptosis proteins such as cIAP-1 and cIAP-2 have recently emerged as the key mechanism in resistance to apoptosis in various cancers and lead to cell survival. Therefore, the present study aimed to evaluate the cIAP-1 and cIAP-2 expression in breast cancer patients, as well as their association with overall patient survival. Methods. Histopathologically confirmed 100 invasive ductal carcinoma patients and healthy controls were included in the present study. Total RNA extraction was done from the serum sample of the patients; further, $100 \mathrm{ng}$ of total RNA was used to synthesise cDNA from patients' as well as from healthy controls' serum. Quantitative real-time PCR was performed using the maxima SYBR Green dye to study the expression of cIAP-1 and cIAP-2, and beta-actin was used as the internal control. Results. The study observed that breast cancer patients had 13.50 mean fold increased cIAP-1 mRNA and 8.76 mean fold increased cIAP-2 mRNA expression compared to the control subjects. Breast cancer patients in the TNM stages I, II, III, and IV showed 9.54, 11.80, 15.19, and 16.83 mean fold increased cIAP-1 mRNA expression $(p=0.004)$. Distant organ metastasis, $(p=0.008)$, PR status of breast cancer patients $(p<0.0001)$, and HER2 status of breast cancer patients $(p<0.0001)$ were found to be associated with cIAP-1 mRNA expression. Breast cancer patients with different TNM stages such as stages I, II, III, and IV showed 7.8, 8.09, 7.97, and 12.85 mean fold increased cIAP-2 mRNA expression $(p=0.0002)$. Breast cancer patients with distant organ metastases status were found to be associated with cIAP-2 mRNA expression $(p<0.0001)$. Breast cancer patients with $<13$-fold and $>13$-fold cIAP- $1 \mathrm{mRNA}$ expression showed 37.39 months and 34.70 months of overall median survival, and the difference among them was found to be significant $(p=0.0001)$. However, cIAP-2 mRNA expression among $<8$-fold and $>8$-fold mRNA expression groups showed 35 months and 27.90 months of overall median survival time $(p<0.0001)$. Higher cIAP-1 mRNA expression was linked with smoking and alcoholism among the breast cancer patients $(p<0.0001$ and $p<0.0001)$. Significant association of higher cIAP-1 mRNA expression was found with the advancement of the disease, while higher mRNA expression of cIAP-1 was associated with distant organ metastases in ROC curve analysis. Conclusion. The present study suggested that increased cell-free cIAP-1 and cIAP2 mRNA expression was correlated with the advancement of disease, progression of disease, and overall reduced patient survival. Cell-free cIAP-1 and cIAP-2 mRNA expression could be the predictive indicator of the disease.
} 


\section{Introduction}

Apoptosis is a highly conserved cell death mechanism carried out by high machinery in our body, and the hallmark step of this mechanism includes the activation of aspartic acidspecific cysteine proteases called caspases [1]. On activation, caspases cleave many substrates within the cell, leading to various structural and physiological alterations associated with apoptotic cells. These apoptotic events include DNA fragmentation, chromatin condensation, nuclear membrane breakdown, and formation of an apoptotic body which can be phagocytized easily [2]. During apoptosis, permeabilization of the mitochondrial membrane leads to the release of cytochrome-C and SMAC/DIABLO (second mitochondria-derived activator of caspase/direct IAP Binding protein with Low PI) from the mitochondrial intermembranal space into the cytosol [3]. To avoid calamitous consequences of apoptosis, caspase functioning in cells is closely controlled by a family of polypeptides known as IAPs (inhibitors of apoptosis). IAP is the presence of approximately 70 amino acids and at least one and up to three baculovirus IAP repeat (BIR) domains which facilitate its binding with caspases and ultimately lead to caspase inhibition. Among these IAPs (cIAP-1 and cIAP-2) and X-linked IAP (XIAP), there exist structural similarities, such as each have three $\mathrm{N}$-terminal BIR domains, followed by a C-terminal RING finger that has ubiquitinprotein isopeptide ligase activity [4]. Cytoplasmic cIAP-1 and cIAP-2 have been shown to inhibit caspases-3, 7 , and 9 by blocking the caspase-active sites with their zinc finger-like BIR domains that directly bind to active caspases $[5,6]$. Overexpression of cIAP-1 and CIAP-2 has diminished the effect on apoptotic activity of the cell, leading to unwanted growth and proliferation, a basic feature of carcinomas [7]. Several studies have suggested the role of IAPs in various signal transduction pathways through which they regulate apoptosis. cIAP-1 and cIAP-2 suppress caspase-8 activation and regulate nuclear factor kappa $\mathrm{B}$ (NF- $\kappa \mathrm{B})$ signaling in response to the tumor necrosis factor (TNF- $\alpha$ ) [8]. cIAP-1 and cIAP-2 also play an important role in TNFR signaling by interacting with TRAF1 and TRAF2. It has been seen that CIAP-1 and cIAP-2 can ubiquitylate TRAF2 and TRAF1, respectively, and can mediate them for proteasome-dependent degradation [9]. It also has been reported that IAPs interact with each other to further enhance their stability and anticaspase activity [10]. Salvesen and Duckett [10] expressed IAP family proteins (cIAP-1 and cIAP-2), tested their association with survivin, and found that both CIAP-1 and cIAP-2 are bound to the survivin protein directly to form the IAP-IAP complex that inhibits apoptosis. Various studies have been conducted in the past to establish the role of SMAC in IAP. SMAC tends to promote caspase-9 activation by neutralizing the inhibitory effect on caspases by interacting with cIAP-1 and cIAP-2 [11].

\section{Materials and Methods}

2.1. Patient Blood Sample Collection and Total RNA Extraction. A total of 100 histopathologically confirmed breast cancer patients and 100 healthy controls were recruited for the study. Three millilitres $(\mathrm{ml})$ of the peripheral blood sample was collected in plain vials, and the serum was separated. Total RNA extraction was done from the serum using the Trizol (Invitrogen) reagent as per the instruction given by the manufacturer and stored at $-80^{\circ} \mathrm{C}$ until an additional necessary step like cDNA synthesis was done. The quality and purity of RNA were determined by the A260/280 ratio using a nanospectrophotometer. This study was ethically approved by the ethical committee, and the work was conducted at Gurukula Kangri University, Haridwar, India.

\subsection{Complementary DNA Synthesis and Quantitative Real-} Time PCR for CIAP-1 and cIAP-2 mRNA Expression. $100 \mathrm{ng}$ of total RNA was used to synthesise cDNA, following manufacturer's protocol (Verso, Thermo Scientific, USA). The cIAP-1 and cIAP-2 mRNA expression was done by quantitative RT-PCR using SYBR Green I technology, and the beta-actin gene was used as the housekeeping control to analyse the fold change in mRNA expression. The primer sequences for cIAP-1 and cIAP-2 mRNA and beta-actin mRNA amplification are depicted in Table 1 . The cIAP-1 and cIAP-2 mRNA expression study was executed by using the programme for 40 cycles, with the first denaturation step at $94^{\circ} \mathrm{C}$ for $35 \mathrm{~s}$, annealing was for $40 \mathrm{~s}$ to $600^{\circ} \mathrm{C}$ with various temperatures, and extension was done at $72^{\circ} \mathrm{C}$ for $40 \mathrm{~s}$, and the final reaction volume was maintained to $20 \mu$ l. The final step for extension was at $72^{\circ} \mathrm{C}$ for 5 minutes. Melting curve analysis was done between the temperature ranges of $35^{\circ} \mathrm{C}$ and $90^{\circ} \mathrm{C}$ for target amplification, and all processes were performed in duplicate to avoid errors. The relative quantification method, 2-( $\triangle \Delta \mathrm{CT})$ method, was used to calculate the cIAP-1 and cIAP-2 mRNA expression using beta-actin as the in-house control, and finally, the results were expressed as the mean fold change in breast cancer patients compared to controls.

2.3. Statistical Analysis. All the data were analysed by using the SPSS 16 version and Graph Pad version 5.03. On the basis of data observation, parametric and nonparametric statistical methods were used to analyse the association of the outcome with different variables. Fold change in cIAP-1 and cIAP-2 mRNA expression was analysed by the 2$(\triangle \Delta C T)$ method. Kaplan-Meier analysis was done to compute breast cancer patient survival. A $p$ value $<0.05$ was considered as statistically significant.

\section{Results}

3.1. Demographic and Clinical Characteristic of Study Subjects. The demographic and clinical characteristics of 100 breast cancer patients and 100 healthy controls are depicted in Table 1 . All patients and healthy controls were females and divided into two age groups: $<45$ years and $>45$ years. In the breast cancer patient $<45$ years of age group, the 
TABle 1: Primer sequences for the amplification of cIAP1, cIAP2, and beta-actin.

\begin{tabular}{lc}
\hline cIAP-1 & $\begin{array}{c}\text { Annealing } \\
\text { temperature }\left({ }^{\circ} \mathrm{C}\right)\end{array}$ \\
\hline Forward: $5^{\prime}$ - & $60^{\circ} \mathrm{C}$ \\
TCAGAATTGGCAAGAGCTGGT R & \\
Reverse: $5^{\prime}$ - & \\
AAATGCCTCCGGTGTTCTGA & \\
cIAP-2 & \\
Forward:5' & \\
GCTTGCAAGTGCGGGTTTTT R & \\
Reverse: $5^{\prime}$ - \\
ACCTTGGAAACCACTTGGCA \\
Beta-actin \\
Forward: $5^{\prime}$ - \\
CGACAACGGCTCCGGCATGTGC-3, \\
Reverse: 5- \\
GTCACCGGAGTCCATCACGATGC-3'. \\
\hline
\end{tabular}

patient percentage was $32 \%$, and in the $>45$ years of age group, it was $68 \%$, while healthy controls were $30 \%$ and $70 \%$, respectively. Further details of the patient characteristics are mentioned in Table 2.

3.2. cIAP-1 mRNA Expression and Clinicopathological Feature of Breast Cancer Patients. It was observed that breast cancer patients had 13.50 mean fold increased cIAP-1 mRNA expression compared to the control subjects (Table 3). Breast cancer patients in TNM stages I, II, III, and IV showed 9.54, $11.80,15.19$, and 16.83 mean fold increased cIAP-1 mRNA expression, and the difference among them was found to be statistically significant, respectively $(p=0.004)$. Breast cancer patients with distant organ metastases showed 16.83 mean fold increased mRNA expression, while nonmetastatic breast cancer patients showed 12.92 mean fold increased cIAP-1 mRNA expression, and the difference among them was found to be significant $(p=0.008)$. Patients with PR- (progesterone receptor-) positive results showed 19.57 mean fold cIAP-1 mRNA expression, while patients negative for PR showed 10.09 mean fold cIAP-1 mRNA expression $(p<0.0001)$. It was observed that patients with HER-2-positive status showed 17.16 mean fold cIAP-1 mRNA expression, while patients with HER-2-negative status showed 9.37 mean fold cIAP-1 mRNA expression $(p<0.0001)$. Higher mRNA expression of cIAP-1 was observed among breast cancer patients who were smokers compared to nonsmoking breast cancer patients $(p<0.0001)$. Patients who were alcoholic also showed a higher mRNA expression of cIAP-1 compared to nonalcoholic patients $(p<0.0001)$.

3.3. cIAP-2 mRNA Expression and Clinicopathological Feature of Breast Cancer Patients. In patients, 8.76 mean fold increased cIAP-2 mRNA expression was observed compared to control subjects (Table 4). Breast cancer patients with different TNM stages such as stages I, II, III, and IV showed 7.8, 8.09, 7.97, and 12.85 mean fold increased cIAP-2 mRNA expression, respectively, and the difference among them was found to be significant $(p=0.0002)$. Breast
TABLE 2: Demographic characteristics of breast cancer patients.

\begin{tabular}{|c|c|c|}
\hline Variables & $\begin{array}{c}\text { Breast cancer patients } \\
\quad N=100(100 \%)\end{array}$ & $\begin{array}{l}\text { Healthy controls } \\
N=100(n=100 \%)\end{array}$ \\
\hline \multicolumn{3}{|l|}{ Age } \\
\hline$<45$ & $32(32)$ & $30(30)$ \\
\hline$>45$ & $68(68)$ & $70(70)$ \\
\hline \multicolumn{3}{|l|}{ TNM stage } \\
\hline Stage I & $3(3)$ & \\
\hline Stage II & $52(52)$ & \\
\hline Stage III & $30(30)$ & \\
\hline Stage IV & $15(15)$ & \\
\hline \multicolumn{3}{|l|}{ Metastases } \\
\hline Yes & $15(15)$ & \\
\hline No & $85(85)$ & \\
\hline \multicolumn{3}{|c|}{ Lymph node involvement } \\
\hline Yes & $54(54)$ & \\
\hline No & $46(46)$ & \\
\hline \multicolumn{3}{|l|}{ Menopause } \\
\hline Yes & $62(62)$ & \\
\hline No & $38(38)$ & \\
\hline \multicolumn{3}{|l|}{ ER } \\
\hline Yes & $41(41)$ & \\
\hline No & $59(59)$ & \\
\hline \multicolumn{3}{|l|}{$\mathrm{PR}$} \\
\hline Yes & $36(36)$ & \\
\hline No & $64(64)$ & \\
\hline \multicolumn{3}{|l|}{ HER2 } \\
\hline Yes & $53(53)$ & \\
\hline No & $47(47)$ & \\
\hline \multicolumn{3}{|l|}{ Smoking } \\
\hline Yes & $28(28)$ & \\
\hline No & $72(72)$ & \\
\hline \multicolumn{3}{|l|}{ Alcoholism } \\
\hline Yes & $32(32)$ & \\
\hline No & $68(68)$ & \\
\hline
\end{tabular}

cancer patients with distant organ metastases showed 12.85 mean fold increased cIAP-2 mRNA expression, while patients without distant organ metastases showed only 8.04fold cIAP-2 mRNA expression, and the difference among them was found to be significant $(p<0.0001)$. However, no such differences in cIAP-2 mRNA expression were seen among other variable groups. No impact of smoking and alcoholism was observed on cIAP-2 mRNA expression among breast cancer patients.

3.4. Correlation of cIAP-1 and cIAP-2 in Breast Cancer Patients. A positive correlation was observed between cIAP1 and cIAP-2 in breast cancer patients (Figure 1). The observed correlation coefficient $(r)$ was 0.21 , and the observed $p$ value was 0.03 . This showed that an increase in cIAP- 1 will tend to increase the cIAP-2 and vice versa.

3.5. Survival Analysis of Breast Cancer Patients with respect to CIAP-1 and CIAP-2. Survival analysis was done to calculate the median survival of breast cancer patients, based on the mean fold expression of cIAP-1 and cIAP-2, and patients were divided into two groups (Figures 2(a) and 2(b)). For 
TABLE 3: Association of clinicopathological features with cIAP-1 mRNA expression in breast cancer patients.

\begin{tabular}{|c|c|c|}
\hline \multirow{2}{*}{ Variables } & \multicolumn{2}{|c|}{ cIAP-1 mRNA expression } \\
\hline & Mean \pm SD & $p$ value \\
\hline Overall expression & $13.50 \pm 8.07$ & - \\
\hline \multicolumn{3}{|l|}{ Age } \\
\hline$<45$ & $13.31 \pm 8.69$ & 0.66 \\
\hline$>45$ & $13.59 \pm 7.83$ & \\
\hline \multicolumn{3}{|l|}{ TNM stage } \\
\hline Stage I & $9.54 \pm 2.91$ & 0.004 \\
\hline Stage II & $11.80 \pm 8.50$ & \\
\hline Stage III & $15.19 \pm 8.16$ & \\
\hline Stage IV & $16.83 \pm 5.17$ & \\
\hline \multicolumn{3}{|l|}{ Distant metastases } \\
\hline Yes & $16.83 \pm 5.17$ & 0.008 \\
\hline No & $12.92 \pm 8.37$ & \\
\hline \multicolumn{3}{|c|}{ Lymph node involvement } \\
\hline Yes & $13.70 \pm 8.72$ & 0.98 \\
\hline No & $13.27 \pm 733$ & \\
\hline \multicolumn{3}{|l|}{ Menopause } \\
\hline Yes & $13.24 \pm 7.24$ & 0.94 \\
\hline No & $13.93 \pm 8.81$ & \\
\hline \multicolumn{3}{|l|}{ ER expression } \\
\hline Yes & $14.83 \pm 9.18$ & 0.28 \\
\hline No & $12.58 \pm 7.14$ & \\
\hline \multicolumn{3}{|l|}{ PR expression } \\
\hline Yes & $19.57 \pm 8.39$ & $<0.0001$ \\
\hline No & $10.09 \pm 5.52$ & \\
\hline \multicolumn{3}{|l|}{ HER2 expression } \\
\hline Yes & $17.16 \pm 7.80$ & $<0.0001$ \\
\hline No & $9.37 \pm 6.22$ & \\
\hline \multicolumn{3}{|l|}{ Smoking } \\
\hline Yes & $21.50 \pm 7.58$ & $<0.0001$ \\
\hline No & $10.39 \pm 5.83$ & \\
\hline \multicolumn{3}{|l|}{ Alcoholism } \\
\hline Yes & $23.14 \pm 6.33$ & $<0.0001$ \\
\hline No & $8.96 \pm 3.54$ & \\
\hline
\end{tabular}

cIAP-1 mRNA expression, groups of $<13$ fold and $>13$ fold were formed, and it was observed that the median survival of breast cancer patients with $<13$-fold cIAP-1 mRNA expression showed 37.39 months of overall median survival time, while the $>13$-fold cIAP-1 mRNA expression group had 34.70 months of overall median survival, and the difference among them was found to be significant $(p=0.001)$.

For cIAP-2 mRNA expression, $<8$ fold and $>8$ fold groups were formed, and it was observed that the median survival of breast cancer patients with $<8$-fold cIAP-2 mRNA expression showed 35 months of overall median survival time, while $>8$-fold cIAP-2 mRNA expression had 27.90 months of overall median survival, and the difference among both groups was found to be statistically significant $(p<0.0001)$.

3.6. Prognostic Importance of cIAP-1 and cIAP-2 mRNA Expression for TNM Stages among Breast Cancer Patients.
TABLE 4: Association of clinicopathological features with cIAP-2 mRNA expression in breast cancer patients.

\begin{tabular}{|c|c|c|}
\hline \multirow{2}{*}{ Variables } & \multicolumn{2}{|c|}{ cIAP-2 mRNA expression } \\
\hline & Mean \pm SD & $p$ value \\
\hline Overall expression & $8.76 \pm 7.16$ & - \\
\hline \multicolumn{3}{|l|}{ Age } \\
\hline$<45$ & $9.43 \pm 8.85$ & \multirow{2}{*}{0.44} \\
\hline$>45$ & $10.97 \pm 9.98$ & \\
\hline \multicolumn{3}{|l|}{ TNM stage } \\
\hline Stage I & $7.80 \pm 6.42$ & \multirow{4}{*}{0.0002} \\
\hline Stage II & $8.09 \pm 8.00$ & \\
\hline Stage III & $7.97 \pm 3.94$ & \\
\hline Stage IV & $12.85 \pm 4.42$ & \\
\hline \multicolumn{3}{|l|}{ Distant metastases } \\
\hline Yes & $12.85 \pm 4.42$ & \multirow{2}{*}{$<0.0001$} \\
\hline No & $8.04 \pm 7.33$ & \\
\hline \multicolumn{3}{|c|}{ Lymph node involvement } \\
\hline Yes & $9.37 \pm 8.18$ & \multirow{2}{*}{0.83} \\
\hline No & $8.80 \pm 4.44$ & \\
\hline \multicolumn{3}{|l|}{ Menopause } \\
\hline Yes & $9.46 \pm 8.47$ & \multirow{2}{*}{0.52} \\
\hline No & $7.62 \pm 4.09$ & \\
\hline \multicolumn{3}{|l|}{ ER expression } \\
\hline Yes & $9.03 \pm 7.59$ & \multirow{2}{*}{0.73} \\
\hline No & $8.89 \pm 7.33$ & \\
\hline \multicolumn{3}{|l|}{ PR expression } \\
\hline Yes & $8.85 \pm 7.94$ & \multirow{2}{*}{0.87} \\
\hline No & $8.07 \pm 6.73$ & \\
\hline \multicolumn{3}{|l|}{ HER2 expression } \\
\hline Yes & $9.30 \pm 7.12$ & \multirow{2}{*}{0.12} \\
\hline No & $8.15 \pm 7.24$ & \\
\hline \multicolumn{3}{|l|}{ Smoking } \\
\hline Yes & $8.96 \pm 8.09$ & \multirow{2}{*}{0.43} \\
\hline No & $8.24 \pm 3.93$ & \\
\hline \multicolumn{3}{|l|}{ Alcoholism } \\
\hline Yes & $9.08 \pm 8.30$ & \multirow{2}{*}{0.54} \\
\hline No & $8.07 \pm 3.77$ & \\
\hline
\end{tabular}

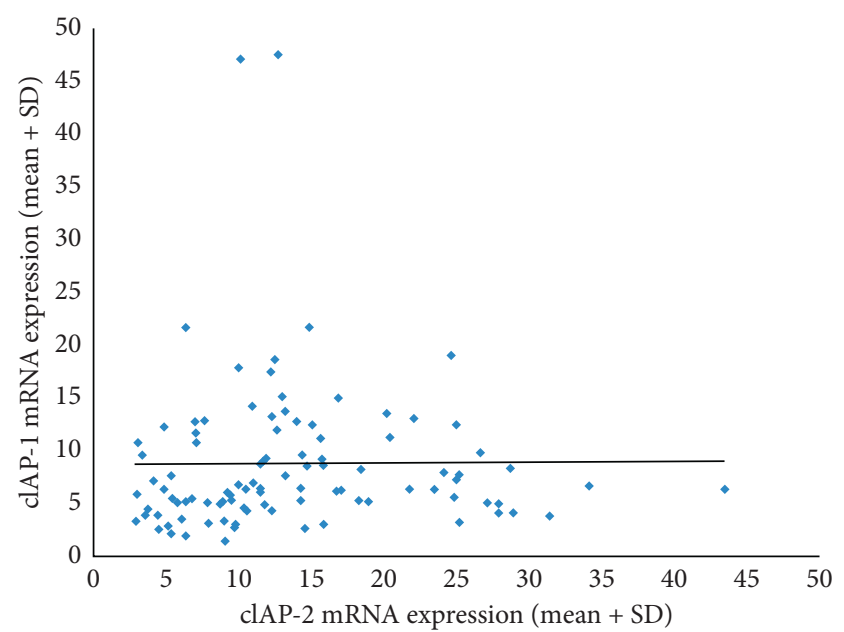

FIgURE 1: Correlation between cIAP-1 and cIAP-2 among breast cancer patients. 


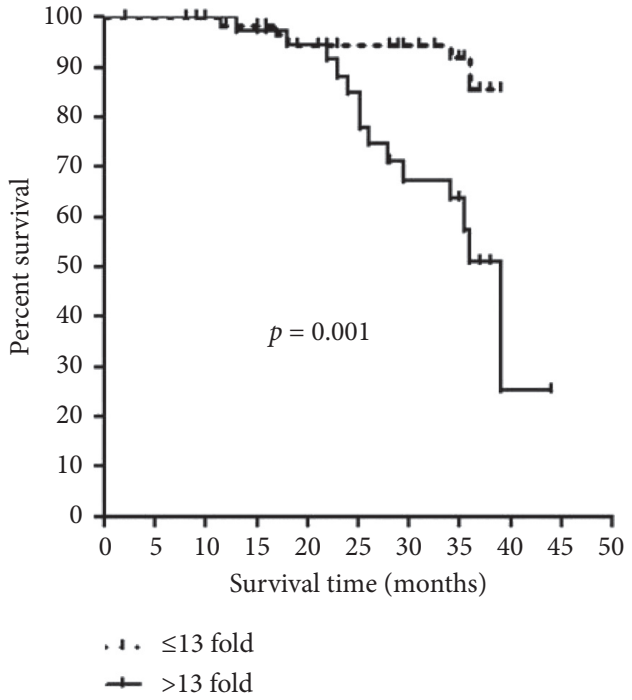

(a)

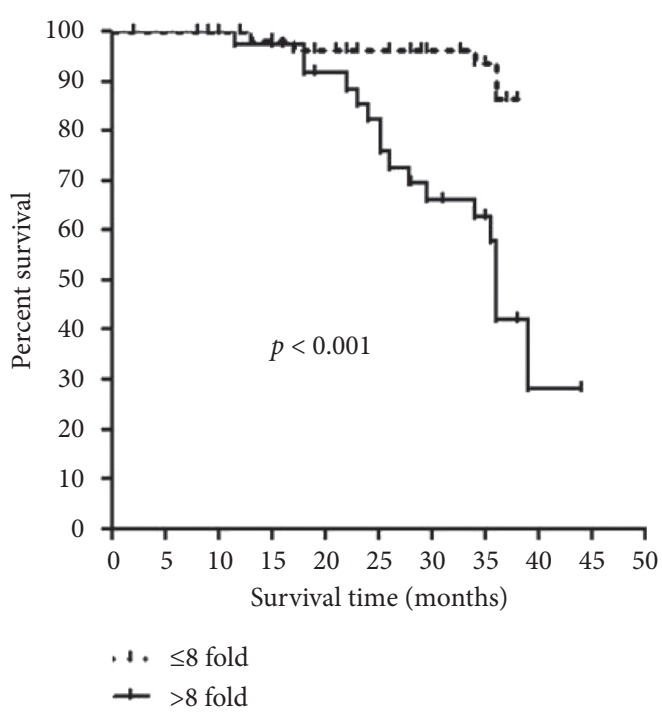

(b)

FiguRE 2: Kaplan-Meier survival curve analysis: (a) cIAP-1 mRNA expression w.r.t breast cancer and (b) cIAP-2 mRNA expression w.r.t breast cancer.

To examine the prognostic significance of CIAP-1 and cIAP2 in breast cancer patients, stages were categorized into two groups, and ROC curve analysis was made (Figure 3). The ROC curve with respect to the early stage vs. advanced stage of breast cancer patients showed a possible cutoff value of 10.67-fold increase for cIAP-1 and 6.39-fold increase for cIAP- 2 and sensitivity was $80 \%$ and $71 \%$ and specificity was $62 \%$ and $60 \%$, respectively (AUC $=0.70, p=0.001$; AUC $=0.69, p=0.001)$ (Table 5).

\subsection{Prognostic Importance of cIAP-1 and cIAP-2 mRNA} Expression for Distant Organ Metastases among Breast Cancer Patients. To examine the prognostic significance of cIAP-1 and cIAP-2 in breast cancer patients, two groups were made: no distant organ metastases and distant organ metastases, and the ROC curve analysis was made (Figure 4). The ROC curve with respect to no distant organ metastases vs distant organ metastases of breast cancer patients showed a possible cutoff value of 12.51-fold increase for cIAP-1 and 8.11-fold increase for cIAP-2 and sensitivity was $73 \%$ and $86 \%$ and specificity was $62 \%$ and $70 \%$, respectively (AUC $=0.71$, $p=0.009 ; \mathrm{AUC}=0.83, p<0.0001)($ Table 6$)$.

\section{Discussion}

Apoptosis modulation-linked molecules can be considered as a new approach in combination with other chemotherapeutic drugs for cancer therapy. This includes important signaling molecules such as inhibitor of apoptosis (IAP) family proteins, which inhibit the apoptosis process. Apoptosis is controlled by IAPs via inhibition and modulation of caspases and the nuclear factor NF-KB transcription factor $[12,13]$. A variety of SMAC mimetics (SM) that can mimic the SMAC and IAP interaction have been developed and showed to accelerate apoptosis by antagonizing IAP action.
More specifically, SMs can inhibit XIAP, rapidly induce degradation, and modulate autocrine TNF- $\alpha$ production and activity for the apoptosis process [14-17].

In the present study, we found that 13.50 mean fold increased cIAP-1 and 8.76 mean fold increased cIAP-2 mRNA expression was observed in breast cancer patients. Increase in cIAP-1 was observed to be associated with TNM stages of disease, distant metastases, PR, and HER2 status, while cIAP-2 was associated with TNM stages of disease and distant metastases only. Increased mRNA expression of cIAP-1 and -2 was found to be linked with disease aggressiveness and development. It was found that increased cIAP-1 and cIAP-2 mRNA expression was associated with reduced breast cancer patient overall survival. Patients who had $<13$ mean fold cIAP-1 expression had better survival compared to $>13$ mean fold cIAP-1 mRNA expression, while $<8$ mean fold cIAP-2 mRNA expression showed better survival compared to $>8$ mean fold increased cIAP- 2 mRNA expression, suggesting that overall the increased cIAP-1 and cIAP-2 mRNA expression was linked with bad prognosis and poor survival. IAPs constitute a family of proteins which stop cell death and control several important signaling pathways [18]. IAPs are often deregulated in tumors and have been connected with poor prognosis by increasing cancer aggressiveness and therapy resistance [19]. SMAC mimetics (SMs) were used to target cellular cIAP-1, cIAP-2, and XIAP [17, 20], and it was found that compounds augment the cytotoxic activity with traditional chemotherapy drugs and prevent IAP-mediated start of several signaling cascades [21]. It has been revealed that IAP alterations are involved in chemotherapeutic drug resistance or other apoptotic molecules in tumor cells [22]. Overexpression of cIAP-2 appears to be liable for sustained neutrophilia in some cases of chronic neutrophilic leukaemia [23]. cIAP-2 has been actively implicated in induction of 


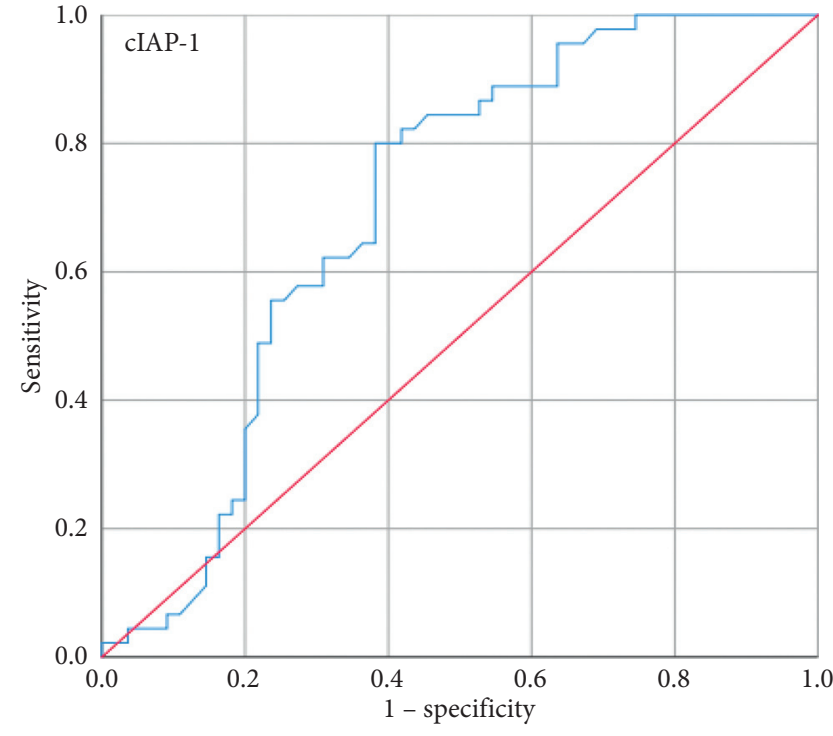

(a)

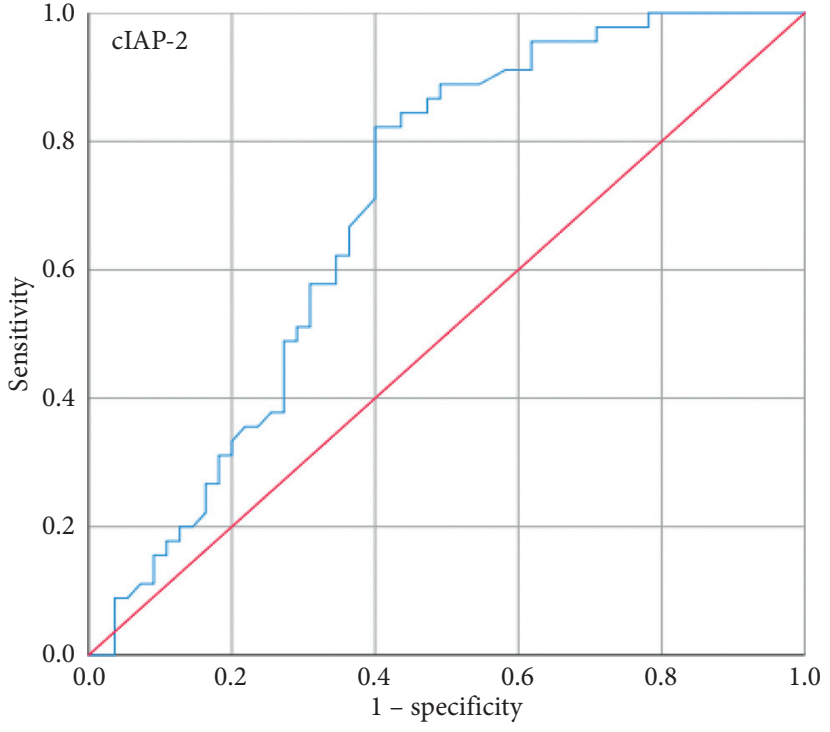

(b)

FIGURE 3: ROC curve (a) for cIAP-1 with respect to early stage vs. advanced stage and (b) for cIAP-2 with respect to early stage vs. advanced stage.

TABLE 5: AUC curve for cIAP-1 and cIAP-2 with respect to the TNM early stage (I and II) and advanced stage (III and IV) of the disease.

\begin{tabular}{lccccc}
\hline Gene & AUC & Cutoff & Sensitivity $(\%)$ & Specificity $(\%)$ & 02 \\
\hline cIAP-1 & 0.70 & 10.67 fold & 80 & 60 & 0.001 \\
cIAP-2 & 0.69 & 6.39 fold & 71 & 60 & 0.001 \\
\hline
\end{tabular}

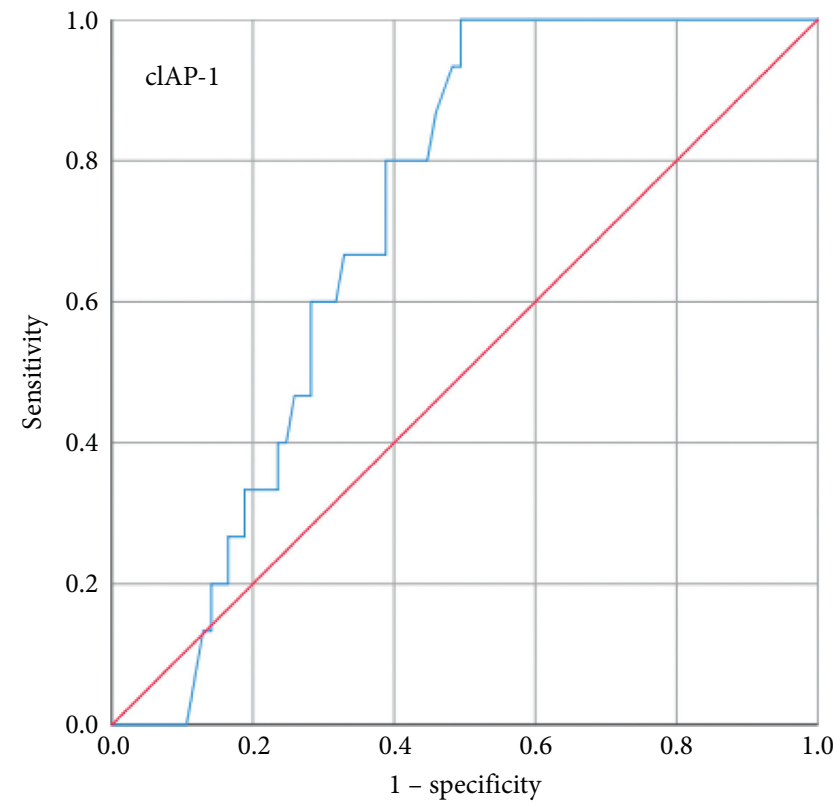

(a)

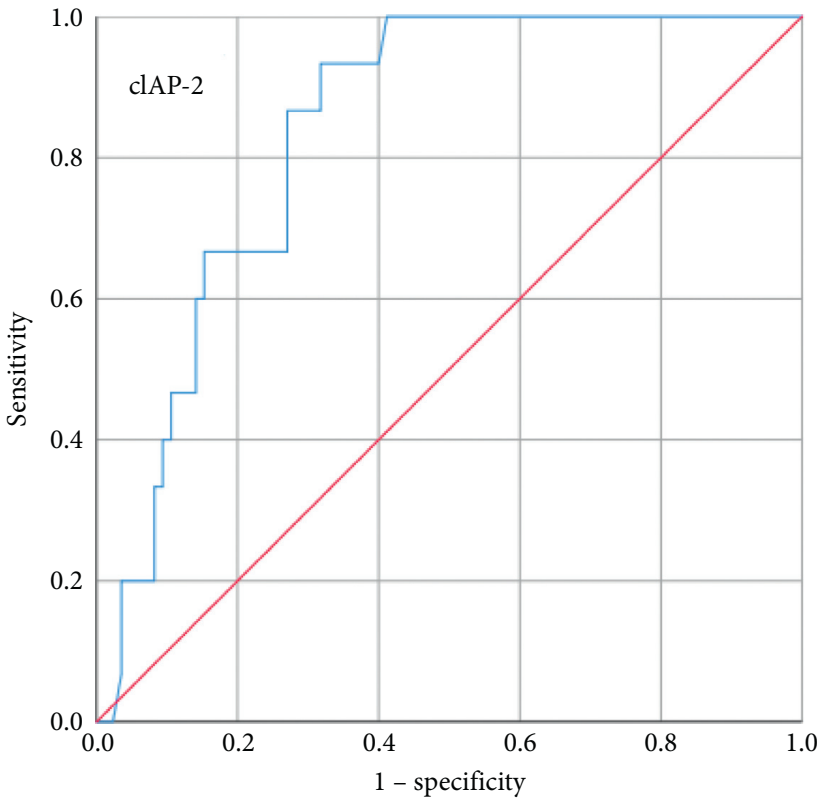

(b)

FIgURE 4: ROC curve (a) for cIAP-1 with respect to no metastases vs. distant organ metastases and (b) for cIAP-2 with respect to no metastases vs. distant organ metastases. 
TABLE 6: AUC curve for cIAP-1 and cIAP-2 mRNA expression with respect to no metastases and distant organ metastases.

\begin{tabular}{lccccc}
\hline Gene & AUC & Cutoff & Sensitivity (\%) & Specificity (\%) & $p$ value \\
\hline cIAP-1 & 0.71 & 12.51 fold & 73 & 62 & 0.009 \\
cIAP-2 & 0.83 & 8.11 fold & 86 & 70 & $<0.0001$ \\
\hline
\end{tabular}

TNF to the ubiquitous transcription factor, NF- $\mathrm{KB}$, and protection from apoptosis [24].

It has been revealed that the epithelial to mesenchymal (EMT) regulation is possibly controlled by the IAPs as one of the important functions [25]. However, the function of IAPs related to EMT regulation and cancer metastasis is still under investigation. A study by Liu Ji in 2012 highlighted that cIAP2 acts as a regulatory factor and could be positive regulators of EMT [26]. It has been reported that cIAP-1 and cIAP-2 play an essential role in NF-кB signal transduction via K63-linked ubiquitination of RIP1 [27]. Furthermore, cIAP-1 and cIAP-2 are also targets of NF-KB-transactivation, suggesting their positive involvement in the regulation of CIAP-1 and cIAP-2 expression [28]. It has been reported that CIAP-1 and cIAP-2 bind to the mitochondrial protein SMAC that competes with caspases for binding to IAPs when released into the cytosol [29]. cIAPs are involved in ubiquitination of several factors such as the TNF receptor-associated factor 2 , serine/threonine kinase NIK, receptor-interacting protein 1, and IAP antagonist SMAC [30, 31]. ROC curve analysis showed that at 10.67 fold or greater than 10.67 fold, cIAP-1 mRNA expression could be indicative for the advancement of the disease, while cIAP-2 at 6.39 fold or greater than 6.39 fold could be indicative for the advancement of the disease. For distant organ metastases, a cutoff value of 12.51 -fold or greater than 12.51 fold cIAP-1 mRNA expression could be indicative of the distant organ metastases, while 8.11-fold or greater than 8.11fold cIAP-2 mRNA expression could be indicative for the distant organ metastases.

\section{Conclusion}

The present study suggests that increased expression of cellfree cIAP-1 and CIAP- 2 was observed in breast cancer patients mainly with the TNM stage and distant organ metastases. Expression of cIAP-1 and cIAP-2 mRNA in our patient cohort was associated with advanced disease progression, poor disease outcome, and overall decreased patient survival for breast cancer. cIAP-1 mRNA higher expression could be the predictive marker for the advancement of disease, while cIAP-2 could be the indicator for distant organ metastases.

\section{Data Availability}

The datasets used and/or analysed during the present study are available from the corresponding author.

\section{Ethical Approval}

The study was approved by the Ethics Committee of GKV, Haridwar, India. "All procedures performed in the studies involving human participants were under the ethical standards of the institutional and/or national research committee and with the 1964 Helsinki Declaration and its later amendments or comparable ethical standards."

\section{Consent}

Written consent was obtained from all participants.

\section{Conflicts of Interest}

The authors declare that they have no conflicts of interest.

\section{Authors' Contributions}

Amit Kumar Verma and Mirza Masroor Ali Beg contributed equally.

\section{Acknowledgments}

The authors would like to acknowledge the support of King Khalid University through a grant (RCAMS/KKU/001/20) under the Research Centre for Advanced Materials Science at King Khalid University, Saudi Arabia. The authors thank all the participants in this study.

\section{References}

[1] H. Y. Chang and X. Yang, "Proteases for cell suicide: functions and regulation of caspases," Microbiology and Molecular Biology Reviews, vol. 64, no. 4, pp. 821-846, 2000.

[2] N. A. Thornberry and Y. Lazebnik, "Caspases: enemies within," Science, vol. 281, no. 5381, pp. 1312-1316, 1998.

[3] D. W. Nicholson, "Baiting death inhibitors," Nature, vol. 410, no. 6824, pp. 33-34, 2001.

[4] C. A. P. Joazeiro and A. M. Weissman, "RING finger proteins," Cell, vol. 102, no. 5, pp. 549-552, 2000.

[5] S. J. Riedl, M. Renatus, R. Schwarzenbacher et al., "Structural basis for the inhibition of caspase- 3 by XIAP," Cell, vol. 104, no. 5, pp. 791-800, 2001.

[6] Q. L. SalvesenLiddington, N. Roy, H. R Stennicke et al., "IAPs block apoptotic events induced by caspase- 8 and cytochrome c by direct inhibition of distinct caspases," The EMBO Journal, vol. 17, no. 8, pp. 2215-2223, 1998.

[7] M. Notarbartolo, M. Cervello, L. Dusonchet, A. Cusimano, and N. D'Alessandro, "Resistance to diverse apoptotic triggers in multidrug resistant HL60 cells and its possible relationship to the expression of P-glycoprotein, Fas and of the novel antiapoptosis factors IAP (inhibitory of apoptosis proteins)," Cancer Letters, vol. 180, no. 1, pp. 91-101, 2002.

[8] T. Samuel, K. Welsh, T. Lober, S. H. Togo, J. M. Zapata, and J. C. Reed, "Distinct BIR domains of cIAP1 mediate binding to and ubiquitination of tumor necrosis factor receptor-associated factor 2 and second mitochondrial activator of caspases," Journal of Biological Chemistry, vol. 281, no. 2, pp. 1080-1090, 2006.

[9] L. Dubrez-Daloz, A. Dupoux, and J. Cartier, "IAPS : more than just inhibitors of apoptosis proteins," Cell Cycle, vol. 7, no. 8, pp. 1036-1046, 2008.

[10] G. S. Salvesen and C. S. Duckett, "IAP proteins: blocking the road to death's door," Nature Reviews Molecular Cell Biology, vol. 3, no. 6, pp. 401-410, 2002. 
[11] C. Du, M. Fang, Y. Li, L. Li, and X. Wang, "SMAC, a mitochondrial protein that promotes cytochrome c-dependent caspase activation by eliminating IAP inhibition," Cell, vol. 102, no. 1, pp. 33-42, 2000.

[12] N. E. Crook, R. J. Clem, and L. K. Miller, "An apoptosisinhibiting baculovirus gene with a zinc finger-like motif," Journal of Virology, vol. 67, no. 4, pp. 2168-2174, 1993.

[13] R. Mannhold, S. Fulda, and E. Carosati, "IAP antagonists: promising candidates for cancer therapy," Drug Discovery Today, vol. 15, no. 5-6, pp. 210-219, 2010.

[14] H. Wu, J. Tschopp, and S. C. Lin, "Smac mimetics and TNF $\alpha$ : a dangerous liaison?” Cell, vol. 131, no. 4, pp. 655-658, 2007.

[15] S. L. Petersen, L. Wang, A. Yalcin-Chin et al., "Autocrine TNF $\alpha$ signaling renders human cancer cells susceptible to smac-mimetic-induced apoptosis," Cancer Cell, vol. 12, no. 5, pp. 445-456, 2007.

[16] E. Harran, J. W. Blankenship, S. M. Wayson et al., "IAP antagonists induce autoubiquitination of c-IAPs, NF- $\kappa \mathrm{B}$ activation, and TNF $\alpha$-dependent apoptosis," Cell, vol. 131, no. 4, pp. 669-681, 2007.

[17] J. E. Zobel, W. W.-L. Wong, N. Khan et al., "IAP antagonists target cIAP1 to induce TNF $\alpha$-dependent apoptosis," Cell, vol. 131 , no. 4 , pp. $682-693,2007$.

[18] M. Benetatos and P. Meier, "IAPs: from caspase inhibitors to modulators of NF- $\kappa \mathrm{B}$, inflammation and cancer," Nature Reviews Cancer, vol. 10, no. 8, pp. 561-574, 2010.

[19] S. Fulda, "Molecular pathways: targeting inhibitor of apoptosis proteins in cancer--from molecular mechanism to therapeutic application," Clinical Cancer Research, vol. 20, no. 2, pp. 289-295, 2014.

[20] D. Benetatos, E. Mastrangelo, L. Belvisi et al., "Dimeric SMAC mimetics/IAP inhibitors as in vivo-active pro-apoptotic agents. Part II: structural and biological characterization," Bioorganic \& Medicinal Chemistry, vol. 20, no. 22, pp. 6709-6723, 2012.

[21] E. De Cesare, T. Goncharov, H. Maecker et al., "Cellular inhibitors of apoptosis are global regulators of NF-B and MAPK activation by members of the TNF family of receptors," Science Signaling, vol. 5, no. 216, p. ra22, 2012.

[22] J. Q. Vucic, X. Jiang, M. Fraser et al., "Role of X-linked inhibitor of apoptosis protein in chemoresistance in ovarian cancer: possible involvement of the phosphoinositide- $3 \mathrm{ki}$ nase/Akt pathway," Drug Resistance Updates, vol. 5, no. 3-4, pp. 131-146, 2002.

[23] T. Tsang, K. Suzuki, C. Sakamoto et al., "Expression of the inhibitor of apoptosis (IAP) family members in human neutrophils: up-regulation of cIAP2 by granulocyte colonystimulating factor and overexpression of cIAP2 in chronic neutrophilic leukemia," Blood, vol. 101, no. 3, pp. 1164-1171, 2003.

[24] N. Tatsumi, C. S. Mitsiades, V. Poulaki et al., "Biologic sequelae of nuclear factor- $\kappa \mathrm{B}$ blockade in multiple myeloma: therapeutic applications," Blood, vol. 99, no. 11, pp. 4079-4086, 2002.

[25] N. S. Munshi and C. S. Duckett, "IAP proteins: regulators of cell migration and development," Current Opinion in Cell Biology, vol. 24, no. 6, pp. 871-875, 2012.

[26] J. Liu, D. Zhang, W. Luo et al., "E3 ligase activity of XIAP RING domain is required for XIAP-mediated cancer cell migration, but not for its Rho GDI binding activity," PLoS One, vol. 7, Article ID e35682, 2012.

[27] S. Fulda and D. Vucic, "Targeting IAP proteins for therapeutic intervention in cancer," Nature Reviews Drug Discovery, vol. 11, no. 2, pp. 109-124, 2012.
[28] S. Julien, I. Puig, E. Caretti et al., "Activation of NF- $\kappa$ B by Akt upregulates Snail expression and induces epithelium mesenchyme transition," Oncogene, vol. 26, no. 53, pp. 7445-7456, 2007.

[29] S. Dargemont and X. Yang, "Cellular inhibitor of apoptosis 1 and 2 are ubiquitin ligases for the apoptosis inducer smac/ DIABLO," Journal of Biological Chemistry, vol. 278, no. 12, pp. 10055-10060, 2003.

[30] L. Wang, F. Du, and X. Wang, "TNF- $\alpha$ induces two distinct caspase-8 activation pathways," Cell, vol. 133, no. 4, pp. 693-703, 2008.

[31] M. J. M. Bertrand, S. Milutinovic, K. M. Dickson et al., "cIAP1 and cIAP2 facilitate cancer cell survival by functioning as E3 ligases that promote RIP1 ubiquitination," Molecular Cell, vol. 30, no. 6, pp. 689-700, 2008. 